\title{
Ventricular Septal Rupture Complicating Acute Myocardial Infarction: Rare and Fatal
}

\author{
Ait Kajate Oussama*, Balouk Ramiz, Zaimi Achraf, Lakhal Zouhair, Atif Benyas \\ Cardiology Center, Military Hospital Mohamed V, Faculty of Medicine and Pharmacy of Rabat, Morocco
}

\author{
DOI: $10.36348 /$ sjmps.2020.v06i08.010 \\ | Received: 18.08 .2020 | Accepted: 26.08 .2020 | Published: 30.08 .2020 \\ *Corresponding author: Ait Kajate Oussama
}

\section{Abstract}

The Ventricular septal rupture (VSR) after acute myocardial infarction is a rare complication. However, the prognosis is improved by early revascularization. But, the mortality is high in country in development. Through this work, we report a case of two ischemic VSR in adult patient of 64 years old, complicated by acute heart failure, with favorable evolution after medical stabilization and surgical suture.

Keywords: Ventricular septal rupture, acute myocardial infarction.

\begin{abstract}
Copyright @ 2020: This is an open-access article distributed under the terms of the Creative Commons Attribution license which permits unrestricted use, distribution, and reproduction in any medium for non-commercial use (NonCommercial, or CC-BY-NC) provided the original author and source are credited.
\end{abstract}

\section{INTRODUCTION}

The development of coronary artery units and the advent of early reperfusion have significantly reduced the hospital mortality of persistent ST-segment elevation myocardial infarction (STEMI). However, in our country, during late management or cardiogenic shock, the mortality remains very high and can be found in this context of mechanical complications of three types: rupture of the free wall of the left ventricle, rupture of the pillar mitral and finally the ventricular septal rupture, all associated with a mortality rate exceeding $90 \%$ under treatment drug. We present the observation of a 64 years old patient, victim of a previous infarction complicated by two ruptures of the interventricular septum.

\section{ObServation}

This is a 64-year-old man, with cardiovascular risk factors chronic smoking at the rate of 25 packs / year, with no significant history, hospitalized one month before his admission to the service in a peripheral hospital for pain thoracic with an anterior myocardial infarction non-revascularized complicated by a systolic dysfunction of the LV, put under medical treatment. The evolution is marked by the worsening of his basic dyspnea becoming stage IV of the NYHA with orthopnea for which he was hospitalized in our training. In addition, he does not report anginal recurrence, syncope or sensory-motor deficit. The clinical examination found a polypneic othopneic patient, blood pressure at $90 / 60 \mathrm{mmHg}$, heart rate at $110 \mathrm{bpm}$, saturation at $92 \%$. We note the presence of a holosystolic murmur of high intensity predominant in the left parasternal, radiating in chariot of the wheel with crackling of the lungs killip III.

The electrocardiogram records a regular sinus rhythm at 110 cycles / min, axis of the heart to the left, plus an extended anterior shift with negative $\mathrm{Q}$ and $\mathrm{T}$ waves in the same territory, without conductive or rhythmic disturbance ( Figure1). The chest radiograph shows cardiomegaly V1, bilateral hilar overload and bilateral alveolo-interstitial syndrome.

In biology, the hemogram is normal, no inflammatory syndrome, correct kidney and liver function; troponin was 2 times the upper limit.

The echocardiography shows an aneurysmal dilation of the septem, left ventricular dysfunction with EF: $35 \%$, high filling pressure and 2 restrictive interventricular communications with left right shunt measuring 8 and $4 \mathrm{~mm}$ respectively (Figure2).

Prescribed treatment includes oxygen therapy, loop diuretic, vasodilators, platelet aggregation inhibitor and a statin. The coronary angiography showed two tight lesions, one on the middle segment of the left anterior descending artery (Figure 3 ) and the other on the second segment of the right coronary artery. (Figure4) 
Ait Kajate et al., Saudi J Med Pharm Sci, August, 2020; 6(8): 581-584

After medical stabilization, the patient underwent a left ventriculotomy with suture by patch of the 2 CIV + double PAC with good postoperative evolution.

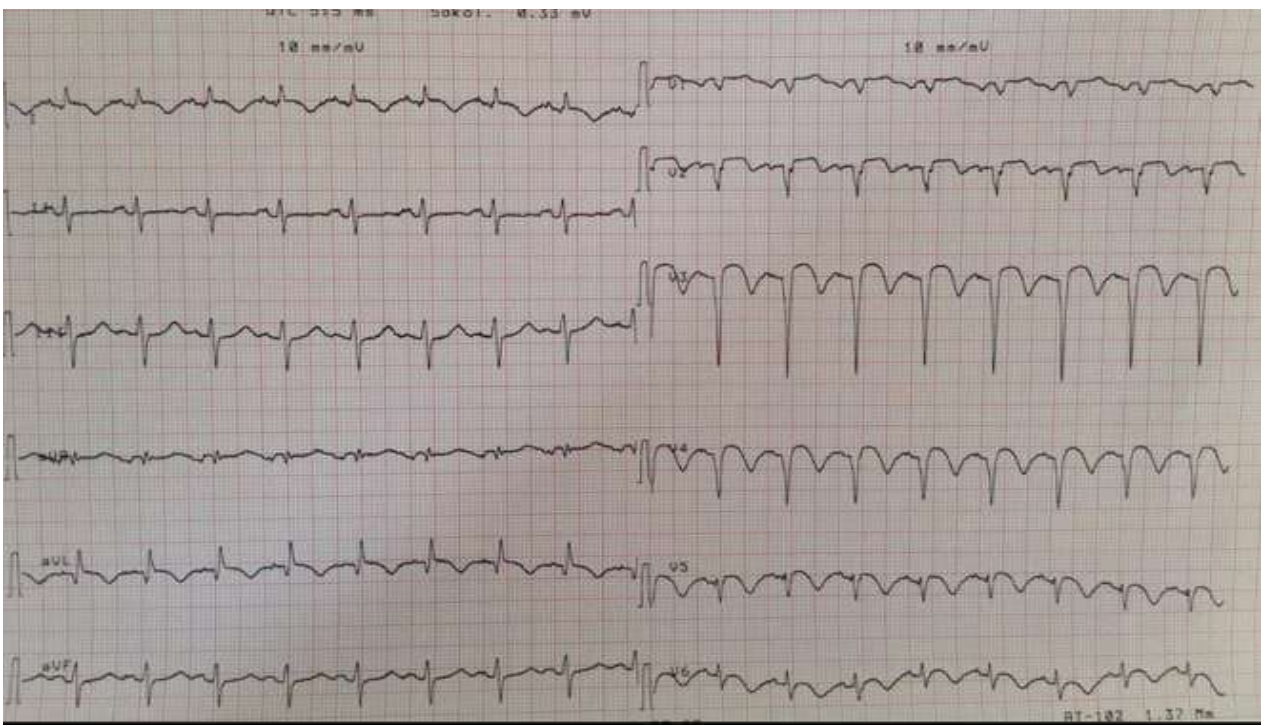

Fig-1: Electrocardiogram shows sequelae of anterior necrosis

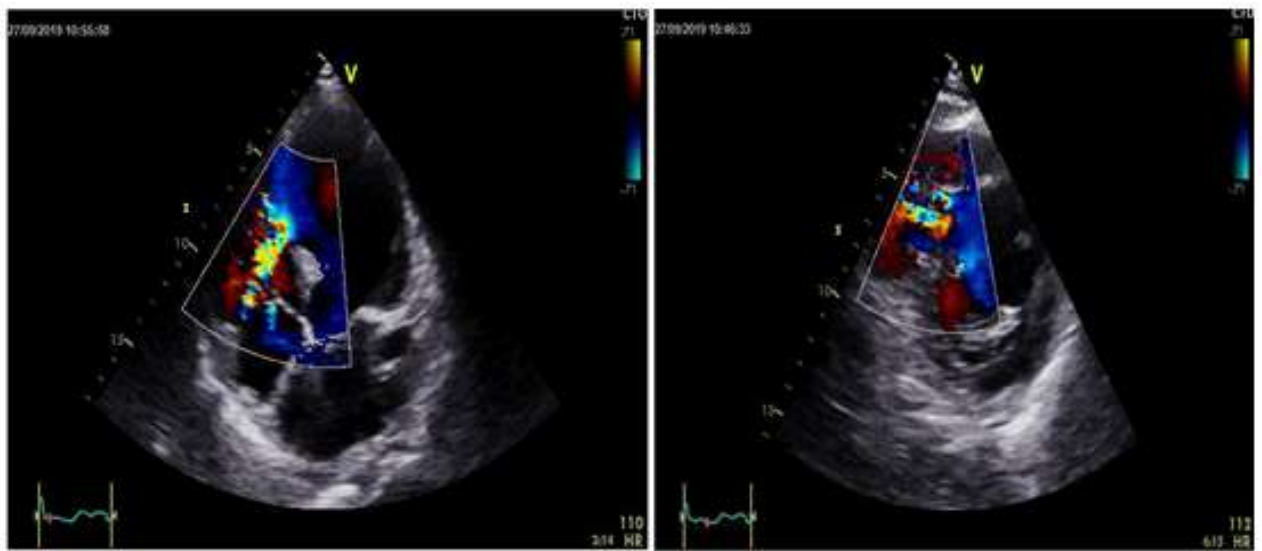

Fig-2: Echocardiography shows two restrictive interventricular communications with left right shunt

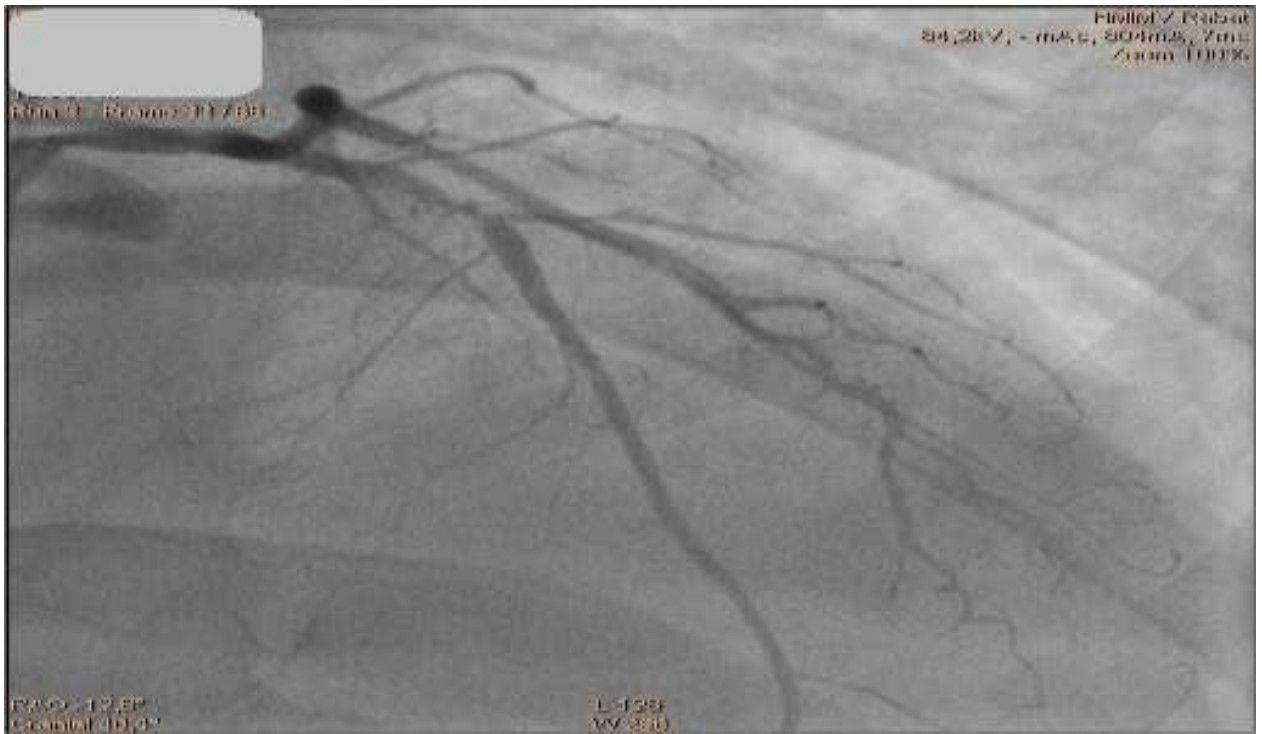

Fig-3: Tight stenosis lesion on the middle segment of the left anterior descending artery 


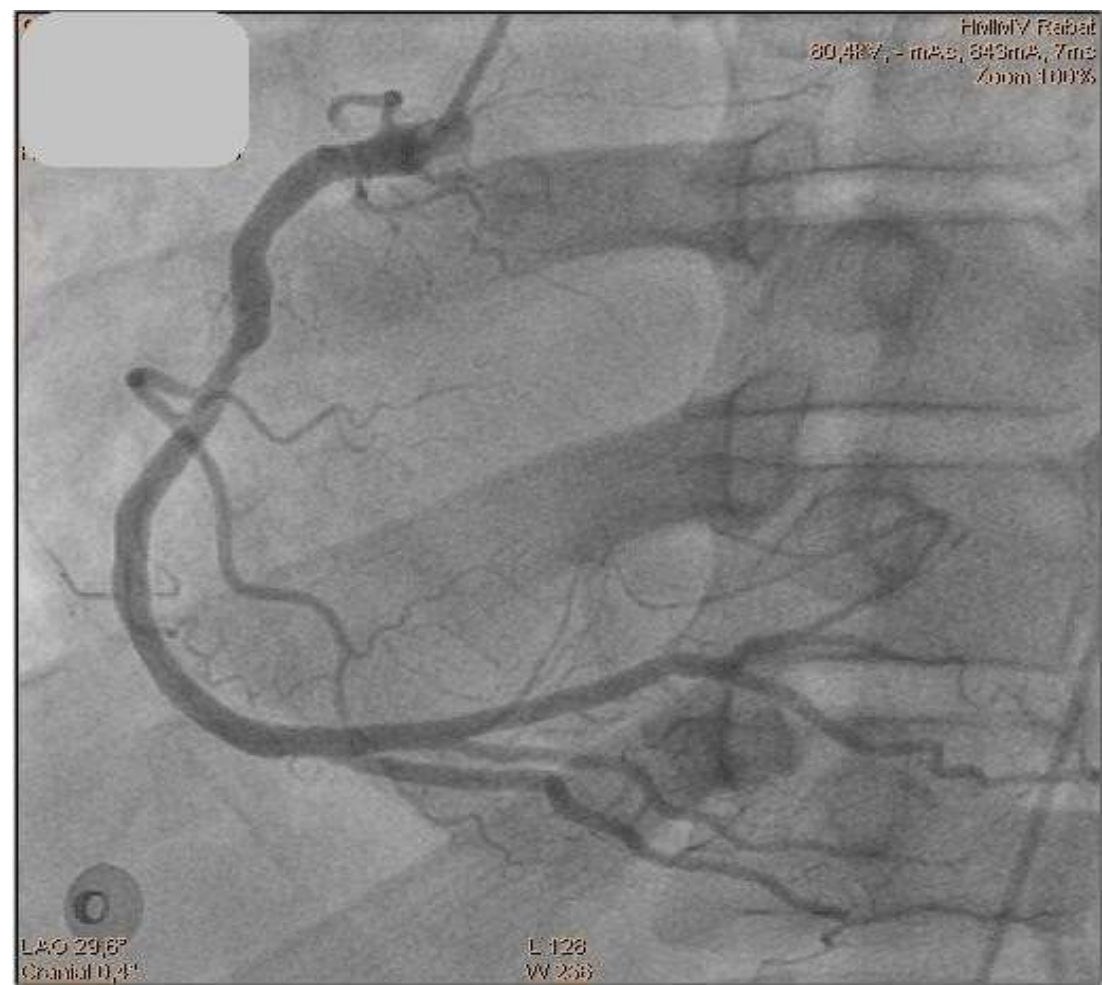

Fig-4: Tight stenosis of the middle segment of the right coronary artery

\section{DISCUSSION}

Ventricular septal rupture (VSR) is a rare but lethal complication of acute myocardial infarction (AMI). The rupture takes place on average within 5-7 days post myocardial infarction [1, 2]. It appears more readily in anterior infarctions of location [3]. Our patient presents a STEMI in anterior topography.

The incidence of VSR represents $0.2 \%$ of all STEMIs, compared to $1-2 \%$ before the start of the revascularization era percutaneous $[1,4]$. Noninterventional mortality is $70 \%$ in intrahospital or 30 days, and $90 \%$ to one year. After a surgical or percutaneous closure, the mortality is $30-40 \%$ at 30 days. [4, 5]

There are several independent risk factors for VSR in patients presenting with AMI. These include older age, female sex, prior stroke, chronic kidney disease, and chronic heart failure [10, 11,12]. Patients who develop VSR are more likely to present with ST segment elevation, initial positive cardiac biomarkers, cardiogenic shock, cardiac arrest, higher Killip class, and longer times to first balloon inflation or thrombolytic administration [6, 7]. The patient has as risk factors a STEMI, killip III and delayed revascularization.

Becker and Mantgem10 classified the pathological features of cardiac free wall rupture into three types. Type I rupture shows an abrupt, slit-like tear, and is associated with acute infarctus, 24 hours in age. Type II rupture demonstrates erosion of the infarcted myocardium, and correlates clinically with a sub-acute presentation. Type III rupture exhibits concomitant aneurysm formation with significant thinning of the septum and subsequent rupture, a process associated with older infarcts. Septal ruptures are further classified as simple or complex. Simple ruptures have a direct connection between the left and right ventricles, occurring at the same level in both chambers, while complex ruptures take a serpigenous course and are more likely to be caused by haemorrhage and irregular tears within the necrotic septum [8]. The VSR of our patient is type III simple.

The anamnesis typically reveals retrosternal pain in 2 stages (the first being the infarction and the second the tear of the interventricular septum) and dyspnea. The clinical examination found a high intensity rasping holosystolic murmur predominant in the left parasternal, radiating in a chariot wheel, signs of heart failure or even cardiogenic shock.

The electrocardiogram usually shows signs of acute or chronic ischemia (ST segment elevation, ST segment offset, T-wave inversions, and presence of pathological Q wave).

Echocardiography makes it possible to pose the diagnosis of certainty with the highlighting of the defect in two-dimensional mode and of the shunt in color Doppler, to locate it, measure its size, calculate the shunt, estimate the systolic pressures of the DV as well as its systolic function and eliminate a severe MI by rupture of the pillar. A coronary angiography should 
be performed after stabilization of the patient to study the coronary anatomy and revascularization according to the timing of the IDM [9].

Therapeutic management begins with hemodynamic stabilization of the patient by the use of vasodilator drugs, diuretics, vasoactive drugs, counterpulsation balloon and the implantation of an ECMO (oxygenation by extra-corporeal membrane) [2, 5]. Then, the surgical closure by patch or percutaneous by Amplatzer device of the septal defect must be generally carried out after 7 days after the IDM to avoid suturing a friable myocardium. After percutaneous closure, dual anti-platelet aggregation for 6 months then aspirin alone and an antibiotic therapy prophylaxis before any invasive procedure are indicated [9].

After medical stabilization that includes oxygen therapy, loop diuretic, vasodilators, platelet aggregation inhibitor and a statin. The patient underwent a left ventriculotomy with suture by patch of the $2 \mathrm{CIV}+$ double PAC with favorable postoperative evolution.

The prognosis is grim with conservative treatment. Indeed, non-interventional mortality is $70 \%$ in intrahospital or 30 days, and $90 \%$ to one year. After a surgical or percutaneous closure, the mortality is 30$40 \%$ at 30 days $[1,3,5]$.

\section{Conclusion}

Septal rupture is a major mechanical complication of myocardial infarction. It is lifethreatening and requires appropriate resuscitation measures before surgery. The diagnosis is by echocardiography. The delayed treatment is a factor of poor prognosis. The means of resuscitation limited in our conditions of exercise strike this prognosis.

\section{REFERENCES}

1. Jones, B. M., Kapadia, S. R., Smedira, N. G., Robich, M., Tuzcu, E. M., Menon, V., \& Krishnaswamy, A. (2014). Ventricular septal rupture complicating acute myocardial infarction: a contemporary review. European heart journal, 35(31), 2060-2068.

2. Mann, D. L., Zipes, D. P., Libby, P., \& Bonow, R. O. (2014). Braunwald's heart disease: a textbook of cardiovascular medicine. Philadelphia, US: Elsevier Health Sciences.

3. Braunwald, E., Zipes, D.P., Libby, P. (2001). Acute Myocardial Infarction. In: Antman EM, Braunwald E, éd. Heart Disease, a text book of cardiovascular medicine. 6e éd. Philadelphia: WB Saunders, 1114-218.
4. Schlotter, F., de Waha, S., Eitel, I., Desch, S., Fuernau, G., \& Thiele, H. (2016). Interventional post-myocardial infarction ventricular septal defect closure: a systematic review of current evidence. Eurointervention: Journal of Europcr in Collaboration with the Working Group on Interventional Cardiology of the European Society of Cardiology, 12(1), 94-102.

5. Testuz, A., Roffi, M., \& Bonvini, R. F. (2013). Left- to- right shunt reduction with intra- aortic balloon pump in postmyocardial infarction ventricular septal defect. Catheterization and Cardiovascular Interventions, 81(4), 727-731.

6. French, J. K., Hellkamp, A. S., Armstrong, P. W., Cohen, E., Kleiman, N. S., O'Connor, C. M., ... \& Mahaffey, K. W. (2010). Mechanical complications after percutaneous coronary intervention in ST-elevation myocardial infarction (from APEX-AMI). The American journal of cardiology, 105(1), 59-63.

7. Yip, H. K., Fang, C. Y., Tsai, K. T., Chang, H. W., Yeh, K. H., Fu, M., \& Wu, C. J. (2004). The potential impact of primary percutaneous coronary intervention on ventricular septal rupture complicating acute myocardial infarction. Chest, 125(5), 1622-1628.

8. Becker, A. E., \& van Mantgem, J. P. (1975). Cardiac tamponade. A study of 50 hearts. European journal of cardiology, 3(4), 349358.

9. Jones, B. M., Kapadia, S. R., Smedira, N. G., Robich, M., Tuzcu, E. M., Menon, V., \& Krishnaswamy, A. (2014). Ventricular septal rupture complicating acute myocardial infarction: a contemporary review. European heart journal, 35(31), 2060-2068.

10. Moreyra, A. E., Huang, M. S., Wilson, A. C., Deng, Y., Cosgrove, N. M., Kostis, J. B., \& MIDAS Study Group. (2010). Trends in incidence and mortality rates of ventricular septal rupture during acute myocardial infarction. The American journal of cardiology, 106(8), 1095-1100.

11. Crenshaw, B. S., Granger, C. B., Birnbaum, Y., Pieper, K. S., Morris, D. C., Kleiman, N. S., ... \& Topol, E. J. (2000). Risk factors, angiographic patterns, and outcomes in patients with ventricular septal defect complicating acute myocardial infarction. Circulation, 101(1), 27-32.

12. López-Sendón, J., Gurfinkel, E. P., Lopez de Sa, E., Agnelli, G., Gore, J. M., Steg, P. G., \& Global Registry of Acute Coronary Events (GRACE) Investigators. (2010). Factors related to heart rupture in acute coronary syndromes in the Global Registry of Acute Coronary Events. European heart journal, 31(12), 1449-1456. 